\title{
Optimization of ultrasonic-assisted extraction of polyphenols and antioxidants from cumin (Cuminum cyminum L.)
}

\author{
Anvar Shamsiev, Jongjin Park, Ibukunoluwa Fola Olawuyi, Golden Odey, Wonyoung Lee* \\ School of Food Science and Biotechnology, Kyungpook National University, Daegu 41566, Korea
}

\begin{abstract}
Ultrasonic-assisted extraction (UAE) using response surface methodology (RSM) was employed for the highly efficient extraction of bioactive compounds such as polyphenols and antioxidants from cumin (Cuminum cyminum L.) seeds. A central composite design (CCD) consisting of three variables and five levels was used to estimate the significance of each process variable in the application of UAE for cumin seed extraction. Process variables optimized were ethanol concentration $(0-80 \%, v / v)$, extraction time (15-75 min), and extraction temperature $\left(15-75^{\circ} \mathrm{C}\right)$. $R S M$ was employed to determine the optimal extraction conditions for the bioactive compounds. Four-dimensional surface plots were generated to indicate polynomial equations of good-fit models. The optimal conditions were then predicted by superimposing these four-dimensional surface plots. Based on the graph for the overlapped contour plots, the optimal UAE conditions: ethanol concentration of $40 \% \mathrm{v} / \mathrm{v}$, extraction time of $51 \mathrm{~min}$, and temperature of $39^{\circ} \mathrm{C}$, were found to give predicted maximal values for yield (20.31\%), total polyphenol content (27.11 $\mathrm{mg} \mathrm{GAE} / \mathrm{g}$ ), antioxidant activity DPPH (52.47\%), and ABTS (41.04\%). Verification experiments were carried out under optimal conditions, and there was a good fit between the estimated and experimental values, suggesting that the model was valid and accurate for the design of UAE process. In conclusion, UAE showed effectiveness in the recovery of valuable antioxidant compounds from cumin.
\end{abstract}

Key words : ultrasonic-assisted extraction, polyphenols, antioxidants, Cuminum cyminum L, response surface methodology

\section{Introduction}

Cumin (Cuminum cyminum L.) is an aromatic herbaceous plant member of the family Apiaceae (Umbelliferae) and is an indigenous plant originated from the East Mediterranean, Egypt, and Turkistan regions. Currently, cumin is widely cultivated in India, Pakistan, Uzbekistan, Iran, Turkey, Morocco, Syria, Chile, Mexico, and China (Tuncturk and Tuncturk, 2006). Cumin seeds are generally known as "Zeera," or "Zira" among the Central Asian countries (Nadeem and Riaz, 2012). In Uzbekistan, cumin is one of the main food ingredients in Uzbekistani cuisines. Cumin seeds are oblong in shape and yellow-gray in color. Since the ancient times, cumin seeds have been widely used in various cuisines, both in whole-seed or in ground forms. Cumin seeds have been used as a traditional food ingredient in countless types of foods, including soups, kormas, and as an ingredient in several types of spice blends for thousands of years. In addition, health benefits such as digestive stimulating, antidiabetic, and anti-inflammatory activities and other health-enhancing effects of cumin have been documented (Srinivasan, 2018). Some studies have suggested that cumin is rich in antioxidants (Bukhari et al., 2009). Cumin seeds extracted using alcohol or water solvents were found to possess many nutraceutical benefits namely, anti-allergic, antioxidant, anti-aggregative, and hypoglycemic

\footnotetext{
*Corresponding author. E-mail : wonyoung@knu.ac.kr, Phone : +82-53-950-7763, Fax : +82-53-950-7762

Received 18 June 2020; Revised 29 October 2020; Accepted 06 November 2020.

Copyright (c) The Korean Society of Food Preservation.

This is an Open Access article distributed under the terms of the Creative Commons Attribution Non-Commercial License (http://creativecommons.org/licenses/by-nc/4.0) which permits unrestricted non-commercial use, distribution, and reproduction in any medium, provided the original work is properly cited.
} 
effect (Sowbhagya, 2013). Hence, cumin and its products, such as cumin extracts, essential oil, and powder, can be a beneficial resource of nutraceuticals rich in bioactive compounds.

A higher content of bioactive compounds extracted from cumin seed is of great importance in the development of improved processing and extraction methods. Various studies have been conducted on identifying the phenolic compounds as well as the antioxidant activity and antimicrobial effects of cumin seed extract and essential oil. Agrawal et al. (2016) evaluated different seed and leaf extracts of cumin and found a high total phenolic and flavonoid content that is associated with their antioxidant properties. In addition, the antioxidant activity of Cuminum cyminum $\mathrm{L}$. was found to be higher than that of some common spices such as $Z$. officinale, $C$. sativum, A. sativum, C. tamala, C. verum, and E. cardamomum (Sultana et al., 2010).

Various thermal extraction methods, such as reflux and Soxhlet extraction, have been applied in the extraction of biologically active compounds and polyphenols from plant materials (Al Juhaimi and Ghafoor, 2013). However, the effectiveness of these methods is compromised by the loss of polyphenols due to oxidation hydrolysis and ionization during extraction, as well as the persistent issue of longer extraction time. Recently, extraction techniques such as ultrasonic-assisted extraction, microwave-assisted extraction, accelerated solvent extraction, and supercritical fluid extraction have been developed for the extraction of polyphenolic compounds from plants (Ong, 2004). Among these techniques, ultrasonic-assisted extraction (UAE) is a simple, economical, and effective alternative to conventional extraction techniques (Ilghami et al., 2015). Additionally, UAE is a quick and effective extraction method that uses ultrasonic waves to create the cavitation effect in the solvent by which the movement of small vacuum bubbles in the liquid increases penetration of the solvent into the raw plant materials (Teng et al., 2014).

Response surface methodology (RSM) was used to optimize the extraction conditions, including extraction temperature, ethanol concentration, and extraction time. RSM is a powerful mathematical and statistical-based technique that is widely used by researchers for the purpose of optimizing the parameters of an extraction procedure
(Bimakr et al., 2012; Ilghami et al., 2015). To the best of our knowledge, many studies have employed RSM to optimize the UAE conditions for the extraction of phenolic compounds (Al Juhaimi and Ghafoor, 2013; Domingos et al., 2008; Haji and Qavamnia, 2015), but there is none on the application of RSM in optimizing UAE for the extraction of bioactive components from cumin seeds $(C$. cyminum L.). Thus, our study aimed to determine the optimal UAE conditions for the extraction of cumin seeds with high yield of total phenol content and antioxidant activity, as well as the ability to absorb free radicals that could be measured using DPPH and ABTS analyses and verified using RSM.

\section{Materials and methods}

\section{Plant material}

Dried cumin (Cuminum Cyminum L.) seed samples were obtained from Hwami Co., Ltd., Incheon, Korea. Cumin seeds were milled into powder form using a laboratory mill (RT-04, Yung Kang, Taiwan). Cumin powder was passed through a $425 \mu \mathrm{m}$ mesh sieve and retained on a $180 \mu \mathrm{m}$ mesh sieve (between the sieves), kept in a polyethylene zip bag, and stored at $-20^{\circ} \mathrm{C}$ until further use. Cumin seed extract was referred to as the cumin extract in this study.

\section{Chemicals and reagents}

All chemicals and solvents used for the extraction procedure, such as organic solvent ethanol and sodium carbonate, were purchased from Duksan Pure Chemical Company (Ansan, Korea).

Gallic acid, Folin-Ciocalteu's phenol reagent, 1,1diphenyl-2-picrylhydrazyl (DPPH) and 2,2'-azino-bis-(3ethylbenzthiazoline-6-sulfonic acid) (ABTS) were obtained from Sigma Chemicals Co. (St. Louis, MO, USA).

\section{Ultrasound-assisted extraction process}

In this study for ultrasonic-assisted extraction (UAE) was consumed the sonication cleaning bath (JAC-3010, KODO, Hwaseong, Korea). The apparatus has the following characteristics: a frequency of $40 \mathrm{kHz}$, an ultrasonic input power of $250 \mathrm{~W}$, and volume of $10 \mathrm{~L}$ (overall size $300 \times$ $240 \times 150 \mathrm{~mm}$ ). One gram of cumin powder was added to the $20 \mathrm{~mL}$ of solvent $(0-80 \%$ of ethanol) in the $50 \mathrm{~mL}$ conical 
tubes $(30 \times 115 \mathrm{~mm})$, then the samples were put in an ultrasonic bath for the extraction. Then the extract was filtered (Whatman No. 1) via a Buchner funnel under vacuum conditions, after then the filtered extract was placid in the $15 \mathrm{~mL}$ conical tubes $(17 \times 120 \mathrm{~mm})$.

\section{Determination of extraction yield}

The extraction yield of cumin extract was defined as total soluble solid content after the evaporation of extraction solvent and moisture. The extraction yield content of cumin extract was determined by gravimetric method (AOAC, 2003). Cumin seeds extract ( $2 \mathrm{~mL}$ ) was placed in a disposable aluminum dish with a diameter of $70 \mathrm{~mm}$ and dried 24 hours in the oven at $105^{\circ} \mathrm{C}$, and then the dish was cooled for 10 minutes before weighing. The weight difference was used to calculate the percentage of the extraction yield content of cumin seeds extract.

$$
\text { Extraction yield }(\%)=\frac{W_{3}-W_{2}}{W_{1}} \times 100
$$

Where $W_{1}$ represents the weight of cumin powder, $W_{2}$ weight of dried cumin extract, $W_{3}$ initial weight of cumin extract before drying.

\section{Total polyphenolics contents (TPC) assay}

TPC was measured using Folin-Ciocalteu's method as previously described (Singleton et al., 1999). Before reaction, cumin seeds extract was diluted well with distilled water and $100 \mu \mathrm{L}$ of diluted samples was a mixed with 50 $\mu \mathrm{L}$ of the Folin-Ciocalteu's reagent and $300 \mu \mathrm{L}$ of $2 \%$ $\mathrm{Na}_{2} \mathrm{CO}_{3}$. After keeping for reaction of the sample at room temperature during $15 \mathrm{~min}, 1 \mathrm{~mL}$ of distilled water was added, and mixture was vortexed quickly before measuring the absorbance at $725 \mathrm{~nm}$. The milligrams of gallic acid equivalents per gram of dry weight (mg GAE/g) was used to express the results.

\section{Determination of DPPH radical scavenging activity}

The cumin extracts antioxidant activity was analyzed as well as the ability to absorb free radicals measured by DPPH assay (Blois, 1958). $100 \mu \mathrm{L}$ Cumin extracts were added to the $90 \mu \mathrm{L}$ of DPPH solution $(1 \mu \mathrm{mol} / \mathrm{L}$ in ethanol). Then the sample was shaken vigorously and kept for the reaction for $30 \mathrm{~min}$ at dark place. Then the decrease in absorbance was measured at $517 \mathrm{~nm}$. The ethanol was used as a control instead of the sample. DPPH was expressed by the following equation:

DPPH radical scavenging $(\%)=$

$$
\left(1-\frac{\text { Absorbance of sample }}{\text { Absorbance of control }}\right) \times 100
$$

\section{Determination of ABTS radical scavenging activity}

ABTS was performed accordingly by the method described by (Shalaby and Shanab, 2013) with some modification. This was on the assumption of the capability of various substances to scavenge ABTS radical cation. The radical cation was prepared by mixing $7 \mathrm{mM} 0.0406 \mathrm{~g}$ ABTS stock solution with $0.007 \mathrm{~g}$ potassium persulfate and leaving the mixture for $12-16 \mathrm{~h}$ in the dark place. Cumin extracts $50 \mu \mathrm{L}$ were reacted with $950 \mu \mathrm{L}$ of ABTS solution. The measurements were taken immediately at $724 \mathrm{~nm}$ after 30 min reaction at dark place. Control was ethanol used instead of the sample. ABTS was calculated by the following equation:

ABTS radical scavenging $(\%)=$

$$
\left(1-\frac{\text { absorbance of sample }}{\text { absorbance of control }}\right) \times 100
$$

\section{Experimental design}

Response surface methodology (RSM) was used to optimize the extraction conditions using a statistical analysis system (SAS) software. There were three independent variables: ethanol concentration $\left(\mathrm{X}_{1}\right)$, extraction time $\left(\mathrm{X}_{2}\right)$, and extraction temperature $\left(\mathrm{X}_{3}\right)$. By using single-factor experiments and central composite design (CCD), the parameters of ethanol concentration $(0,20,40,60$, and $80 \%$ ), extraction time $(15,30,45,60$, and $75 \mathrm{~min})$, and extraction temperature $\left(15,30,45,60\right.$, and $\left.75^{\circ} \mathrm{C}\right)$ were selected as suitable conditions and were encoded at five levels $(-2,-1,0,+1$, and +2$)$ (Table 1). The CCD matrices consisted of six center points, eight factorial points, and six axis points at a distance of \pm 2 , which led to a total of 20 sets of experimental runs. The experimental data were combined into a second-order empirical polynomial model using regression analysis as presented in the following equation: 
Table 1. The central composite design for optimization of UAE condition for cumin

\begin{tabular}{ccccccc}
\hline & & \multicolumn{5}{c}{ Levels } \\
\cline { 2 - 6 } $\mathrm{X}_{\mathrm{n}}$ & Response variables & -2 & -1 & 0 & +1 & +2 \\
\hline $\mathrm{X}_{1}$ & $\begin{array}{c}\text { Extraction } \\
\left.\text { temperature ( }{ }^{\circ} \mathrm{C}\right)\end{array}$ & 15 & 30 & 45 & 60 & 75 \\
$\mathrm{X}_{2}$ & $\begin{array}{c}\text { Ethanol } \\
\text { concentration (\%) }\end{array}$ & 0 & 20 & 40 & 60 & 80 \\
$\mathrm{X}_{3}$ & $\begin{array}{c}\text { Extraction } \\
\text { time (min) }\end{array}$ & 15 & 30 & 45 & 60 & 75 \\
\hline
\end{tabular}

$$
Y=\beta_{0}+\sum_{i=1}^{k} \beta_{i} x_{i}+\sum_{i=1}^{k} \beta_{i i} x_{i}^{2}+\sum_{1 \leq i \leq j}^{k} \beta_{i j} x_{i} x_{j}+\epsilon
$$

where $\mathrm{Y}$ symbolizes the independent responses; $\beta_{0}, \beta_{\mathrm{i}}, \beta_{\mathrm{ii}}$, and $\beta_{\mathrm{ij}}$ are the regression coefficients of the process variables for the intercept, linear, quadratic, and crossproduct terms; respectively, and symbolizes the error. The statistical significance of the coefficients in the regression equation was verified using the SAS software. The suitability of the polynomial model equation for the predicted response was evaluated using coefficient $\mathrm{R}^{2}$.

\section{Determination of phenolics compounds using HPLC}

The cumin extracts obtained under optimal conditions were analyzed for phenolic compounds using the method described by Seal (2016). The HPLC system (Jasco International Co. Ltd., Tokyo, Japan) consisted of a UV detector (UV-2075 plus, Jasco International Co. Ltd.) and a $\mathrm{C}_{18}$ reversed-phase column $(250 \times 4.6 \mathrm{~mm}, 5 \mu \mathrm{m})$. The column was eluted using $1 \%$ acetic acid aqueous solution (A) and acetonitrile (B) at a flow rate of $0.7 \mathrm{~mL} / \mathrm{min}$. The elution gradient was as follows: $0-10 \% \mathrm{~B}, 28-40 \% \mathrm{~B}, 39$ $60 \% \mathrm{~B}$, and $50-90 \% \mathrm{~B}$. The UV detector was set at 272 $\mathrm{nm}$, and the injection volume was $20 \mu \mathrm{L}$. Catechin, caffeic acid, syringic acid, $p$-coumaric acid, rutin, ferulic acid, myricetin, quercetin, and kaempferol were obtained from Sigma Aldrich Co. (St. Louis, MO, USA) and were used as standard materials.

\section{Statistical analysis}

All experiments were performed in triplicate, and results were expressed as mean \pm standard deviation. Four-dimensional response surface plots were obtained using the Mathematica program (Version 12.0, Wolfram, Champaign, IL, USA) and SAS software (Version 9.2, SAS Institute Inc., Cary, NC, USA).

\section{Results and discussion}

\section{Modelling of the UAE process}

In optimization studies, a second-order polynomial model is an official empirical model that is generally used by process engineers (Myers and Montgomery, 2009). Table 1 shows the CCD for optimized UAE conditions for cumin seeds, which was illustrated in the model using the least-squares method. SAS software was used to define the significance and adequacy of the selected model. The CCD matrix indicating extraction yield, TPC, DPPH, and ABTS radical scavenging activities of cumin seed extracts using UAE is summarized in Table 2. Results of the three target responses from the $\mathrm{CCD}$ matrix were also subjected to analysis using SAS software. The second polynomial equations for the quality prediction of cumin extract are shown in Table 3 . The reliability of the model was confirmed by the values of coefficient of determination, $\mathrm{R}^{2}$, which are represented by the regression equations shown in Table 3. The fitted model showed the following $\mathrm{R}^{2}$ values for yield (0.9077), TPC (0.9131), DPPH (0.9008), and ABTS (0.8882). To predict the correlation between independent process variables and dependent responses, four-dimensional surface plots were created. The type of solvent plays an important role in the extraction of biologically active compounds from plant sources (Wang et al., 2008). Therefore in this study, ethanol was used as the extraction solvent due to its low toxicity and easy recovery using reduced-pressure distillation (Wang et al., 2008).

\section{Effects of extraction conditions on extraction yield}

The experimental results for extraction yield are presented in Table 2. The coefficient of determination for the polynomial equation was 0.9077 and significance was less than $0.001 \%$ (Table 3 ). The peak point of the extraction yield was $22.1 \%$ in the test run 4 under following UAE conditions: the extraction temperature of $30^{\circ} \mathrm{C}$, the ethanol concentration of $60 \%$ and an extraction time of 60 minutes. While the lowest yield was $11.9 \%$ in run 12 , which used conditions of extraction temperature of $45^{\circ} \mathrm{C}$, ethanol 
Table 2. Central composite design for ultrasonic-assisted extraction from cumin and the extraction yield, total polyphenolics, and antioxidant activity (DPPH, ABTS) of the extracts

\begin{tabular}{|c|c|c|c|c|c|c|c|}
\hline \multirow[b]{2}{*}{ Test runs } & \multicolumn{3}{|c|}{ Independent variables } & \multicolumn{4}{|c|}{ Measured responses } \\
\hline & $\begin{array}{c}\text { Extraction } \\
\text { temperature } \\
\mathrm{X}_{1}\left({ }^{\circ} \mathrm{C}\right)\end{array}$ & $\begin{array}{c}\text { Ethanol } \\
\text { concentration } \\
\mathrm{X}_{2}(\%)\end{array}$ & $\begin{array}{c}\text { Extraction } \\
\text { time } X_{3} \\
\text { (min) }\end{array}$ & $\begin{array}{l}\text { Yield } \\
(\%)\end{array}$ & $\begin{array}{c}\text { TPC } \\
\text { (mg GAE/g) }\end{array}$ & $\begin{array}{c}\text { DPPH } \\
(\%)\end{array}$ & $\begin{array}{c}\mathrm{ABTS} \\
(\%)\end{array}$ \\
\hline 1 & $30(-1)^{1)}$ & $20(-1)$ & $30(-1)$ & $20.75 \pm 0.07^{2)}$ & $24.14 \pm 0.20$ & $51.72 \pm 0.17$ & $31.19 \pm 0.06$ \\
\hline 2 & $30(-1)$ & $20(-1)$ & $60(1)$ & $21.70 \pm 0.42$ & $23.91 \pm 0.44$ & $52.82 \pm 0.23$ & $30.27 \pm 0.28$ \\
\hline 3 & $30(-1)$ & $60(1)$ & $30(-1)$ & $18.35 \pm 0.35$ & $25.41 \pm 0.17$ & $53.74 \pm 0.50$ & $31.75 \pm 0.42$ \\
\hline 4 & $30(-1)$ & $60(1)$ & $60(1)$ & $22.10 \pm 0.57$ & $27.49 \pm 0.17$ & $54.92 \pm 0.34$ & $30.84 \pm 0.16$ \\
\hline 5 & $60(1)$ & $20(-1)$ & $30(-1)$ & $18.20 \pm 0.14$ & $20.96 \pm 0.10$ & $46.44 \pm 0.70$ & $43.76 \pm 0.28$ \\
\hline 6 & $60(1)$ & $20(-1)$ & $60(1)$ & $17.07 \pm 0.04$ & $20.32 \pm 0.26$ & $37.49 \pm 0.69$ & $39.48 \pm 0.95$ \\
\hline 7 & $60(1)$ & $60(1)$ & $30(-1)$ & $13.30 \pm 0.42$ & $21.94 \pm 0.52$ & $50.93 \pm 0.43$ & $44.59 \pm 0.41$ \\
\hline 8 & $60(1)$ & $60(1)$ & $60(1)$ & $13.25 \pm 0.07$ & $19.11 \pm 0.56$ & $46.59 \pm 0.76$ & $38.25 \pm 0.06$ \\
\hline 9 & $15(-2)$ & $40(0)$ & $45(0)$ & $17.75 \pm 0.21$ & $22.40 \pm 0.36$ & $50.74 \pm 0.17$ & $26.08 \pm 0.31$ \\
\hline 10 & $75(2)$ & $40(0)$ & $45(0)$ & $13.75 \pm 0.21$ & $18.36 \pm 0.20$ & $38.82 \pm 0.40$ & $33.71 \pm 0.36$ \\
\hline 11 & $45(0)$ & $0(-2)$ & $45(0)$ & $21.55 \pm 0.21$ & $22.40 \pm 0.61$ & $42.26 \pm 0.34$ & $38.65 \pm 0.52$ \\
\hline 12 & $45(0)$ & $80(2)$ & $45(0)$ & $11.90 \pm 0.00$ & $20.44 \pm 0.56$ & $43.27 \pm 0.47$ & $33.71 \pm 0.41$ \\
\hline 13 & $45(0)$ & $0(-2)$ & $15(-2)$ & $19.20 \pm 0.28$ & $16.91 \pm 0.76$ & $36.88 \pm 0.39$ & $35.31 \pm 0.27$ \\
\hline 14 & $45(0)$ & $40(0)$ & $75(2)$ & $19.10 \pm 0.00$ & $25.29 \pm 0.10$ & $51.93 \pm 0.40$ & $42.33 \pm 0.48$ \\
\hline 15 & $45(0)$ & $40(0)$ & $45(0)$ & $19.50 \pm 0.28$ & $27.14 \pm 0.52$ & $49.84 \pm 0.45$ & $43.11 \pm 0.21$ \\
\hline 16 & $45(0)$ & $40(0)$ & $45(0)$ & $18.90 \pm 0.57$ & $26.33 \pm 0.61$ & $50.51 \pm 0.34$ & $43.18 \pm 0.37$ \\
\hline 17 & $45(0)$ & $40(0)$ & $45(0)$ & $19.10 \pm 0.28$ & $25.93 \pm 0.69$ & $50.74 \pm 0.36$ & $43.79 \pm 0.37$ \\
\hline 18 & $45(0)$ & $40(0)$ & $45(0)$ & $19.85 \pm 0.07$ & $26.85 \pm 0.89$ & $51.07 \pm 0.39$ & $43.69 \pm 0.45$ \\
\hline 19 & $45(0)$ & $40(0)$ & $45(0)$ & $19.30 \pm 0.14$ & $26.57 \pm 1.02$ & $49.88 \pm 0.45$ & $44.13 \pm 0.21$ \\
\hline 20 & $45(0)$ & $40(0)$ & $45(0)$ & $19.65 \pm 0.07$ & $27.03 \pm 0.70$ & $50.89 \pm 0.34$ & $43.89 \pm 0.27$ \\
\hline
\end{tabular}

${ }^{1)}$ Values in brackets were coded levels for process variables according to CCD.

${ }^{2)}$ Analytical results represented by mean $\pm \mathrm{SD}(\mathrm{n}=3)$.

Table 3. The second polynomial equations for quality prediction of cumin

\begin{tabular}{|c|c|c|c|}
\hline Response $^{1)}$ & The second polynomial equations & $\mathrm{R}^{2}$ & Significance \\
\hline Yield & $\begin{array}{l}Y_{\text {YIELD }}=4.973137+0.481310 X_{1}+0.129210 X_{2}+0.241916 X_{3}-0.004288 X_{1}^{2}-0.002375 X_{2} X_{1} \\
-0.001878 X_{2}^{2}-0.002611 X_{3} X_{1}+0.000723 X_{3} X_{2}-0.001442 X_{3}^{2}\end{array}$ & 0.9077 & $<0.0001$ \\
\hline ТPC & $\begin{array}{l}\mathrm{Y}_{\mathrm{TPC}}=87.393505+0.350929 \mathrm{X}_{1}-1.231400 \mathrm{X}_{2}-0.403142 \mathrm{X}_{3}-0.002541 \mathrm{X}_{1}^{2}-0.002839 \mathrm{X}_{2} \mathrm{X}_{1} \\
+0.009258 \mathrm{X}_{2}^{2}+0.004555 \mathrm{X}_{3} \mathrm{X}_{1}+0.000830 \mathrm{X}_{3} \mathrm{X}_{2}+0.001580 \mathrm{X}_{3}^{2}\end{array}$ & 0.9131 & 0.0012 \\
\hline DPPH & $\begin{array}{l}Y_{\mathrm{DPPH}}=87.393505+0.350929 \mathrm{X}_{1}-1.231400 \mathrm{X}_{2}-0.403142 \mathrm{X}_{3}-0.002541 \mathrm{X}_{1}^{2}-0.002839 \mathrm{X}_{2} \mathrm{X}_{1} \\
+0.009258 \mathrm{X}_{2}^{2}+0.004555 \mathrm{X}_{3} \mathrm{X}_{1}+0.000830 \mathrm{X}_{3} \mathrm{X}_{2}+0.001580 \mathrm{X}_{3}^{2}\end{array}$ & 0.9008 & 0.0003 \\
\hline ABTS & $\begin{array}{l}\mathrm{Y}_{\mathrm{ABTS}}=-51.279498+1.408106 \mathrm{X}_{1}+2.399036 \mathrm{X}_{2}-0.073583 \mathrm{X}_{3}-0.017720 \mathrm{X}_{1}^{2}- \\
0.002249 \mathrm{X}_{2} \mathrm{X}_{1}-0.014428 \mathrm{X}_{2}^{2}+0.002687 \mathrm{X}_{3} \mathrm{X}_{1}-0.010510 \mathrm{X}_{3} \mathrm{X}_{2}+0.004881 \mathrm{X}_{3}^{2}\end{array}$ & 0.8882 & 0.0032 \\
\hline
\end{tabular}

\footnotetext{
${ }^{1)}$ Yield, total soluble solid yield; TPC, total phenolic content; DPPH, DPPH radical scavenging activity; ABTS, ABTS radical scavenging activity.
} 
concentration of $80 \%$, and extraction time of 45 minutes. Based on the second polynomial equation (Table 3 ), fourdimensional response surface plots were created and shown in Fig. 1A-D. In the Fig. 1A showed four-dimensional response surface plots presenting constant levels for yield of $18,19,20$ and $22 \%$. This figure reflected the effects of variables in UAE process, including extraction temperature, ethanol concentration, and sonication time on yield. The yield of more than $20 \%$ could be obtained at a low temperature range of $15-35^{\circ} \mathrm{C}$ for $45-75 \mathrm{~min}$ or at a high temperature range for $35-55^{\circ} \mathrm{C}$ for $25-45 \mathrm{~min}$. Our result suggested that higher temperature benefit yield extraction
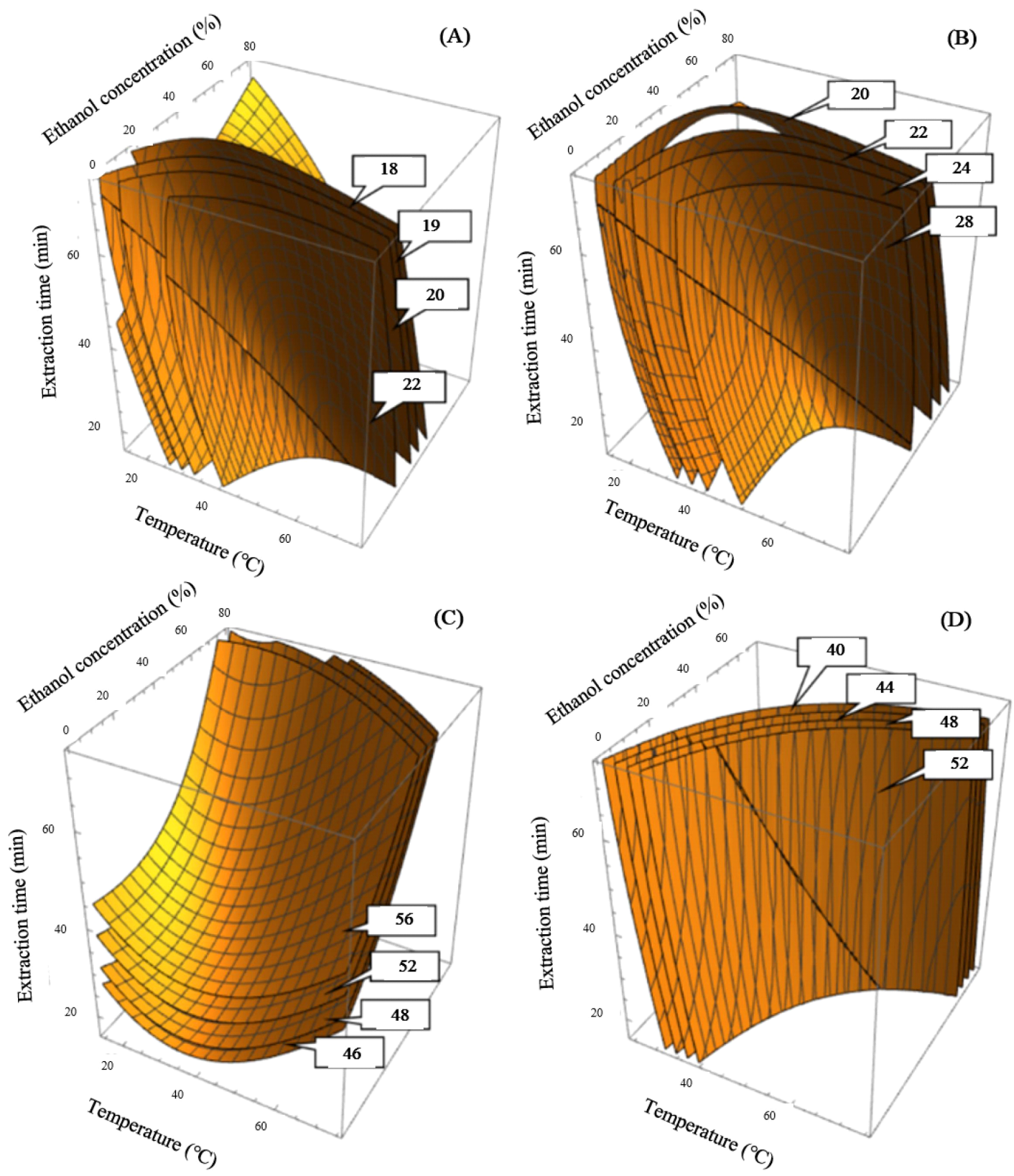

Fig. 1. Four-dimensional response surfaces for response variables according to extraction conditions.

A, extraction yield at constant values $(18,19,20,22 \%)$; B, total polyphenol content at constant values $(20,22,24,28 \mathrm{mg}$ GAE/g); C, DPPH radical scavenging activity at constant values $(46,48,52,56 \%)$; D, ABTS radical scavenging activity at constant values $(40,44,48,52 \%)$ as a function of ethanol concentration (\%), extraction time (min), and extraction temperatures $\left({ }^{\circ} \mathrm{C}\right)$. 
and reduce extraction time, science higher extraction temperature could increase the movement of solvent molecules and accelerate mass transfer ratios, thus, reducing the extraction time. Extraction of solids and liquids is a mass transfer phenomenon in which solids contained in a matrix are transferred to a solvent that comes into contact with the matrix (Ghafoor et al., 2009). This mass transfer phenomenon can be improved by varying the diffusion coefficients caused by ultrasound and extraction temperature. Ultrasonic waves destroy plant matrix cells and contribute to the release of cell contents into the extraction medium (Vinatoru et al., 1997). These were also explained by Corrales (2008) that the phenomenon of mass transfer at elevated temperature increases the internal liquid phase, which increases the pressure, causing centrifugal circulation of dissolved substances through the installation elements. In addition, heat treatment can also destroy the bonds of the phenolic matrix and affect the membrane structure of plant cells, making them less selective due to coagulation of lipoproteins (Corrales et al., 2008).

In Fig. 1A, the extraction yield increased substantially with the increase in ethanol concentration, and a satisfactory yield of more than $20 \%$ could be reached at an ethanol concentration range of $20-60 \%$. The effect of ethanol concentration on the yield can be explained by the fact that adding water to ethanol improves the extraction rate (Tomšik et al., 2016).

The model predicted a highest extraction yield of $20.31 \%$ under the following extraction conditions: $\mathrm{X}_{1}=39^{\circ} \mathrm{C}, \mathrm{X}_{2}=$ $40 \%$ and $X_{3}=51 \mathrm{~min}$. The experimental extraction yield value of $21.0 \%$ was almost same with the model-predicted value $(20.31 \%)$. The highly substantial effect was found in ethanol concentration and extraction temperature, as can be seen from the graph of the reaction surface $4 \mathrm{D}$, shown in Fig. 1A. Thus, the extraction temperature $\left(30-45^{\circ} \mathrm{C}\right)$, ethanol concentration $(20-60 \%)$ and extraction time $(45-60 \mathrm{~min})$ showed favorable results for yield of cumin seeds extract.

\section{Effects of extraction conditions on TPC}

Our experimental data for TPC are presented in Table 2. The $\mathrm{R}^{2}$ for a polynomial equation was 0.9131 at a significance level of $p<0.005$ (Table 3). The peak point of TPC at 27.49 $\mathrm{mg} \mathrm{GAE} / \mathrm{g}$ was observed at an ethanol concentration of $60 \%$, extraction temperature of $30^{\circ} \mathrm{C}$, and extraction time of $60 \mathrm{~min}$ (Run 4, Table 2). The lowest TPC of $16.91 \mathrm{mg}$ $\mathrm{GAE} / \mathrm{g}$ was obtained in test run 13 , in which distilled water was used as a solvent for the extraction at $45^{\circ} \mathrm{C}$ for $15 \mathrm{~min}$. The predicted maximum TPC was $27.1 \mathrm{mg} \mathrm{GAE} / \mathrm{g}$ (Table 4). The response surface plots indicated the highest predicted peak point of TPC at constant values of 20, 22, 24, and 28 mg GAE/g (Fig. 1B). Accordingly, for the four-dimensional response surface plot results, optimum extraction conditions for satisfactory TPC of more than $25 \mathrm{mg}$ GAE/g comprised the extraction temperature $\left(30-45^{\circ} \mathrm{C}\right)$, ethanol concentration (20-40\%), and sonication time (30-45 $\mathrm{min})$.

According to Murakami et al. (2004), heat treatment can destroy the cell wall and subcellular compartments of plant materials to release more components. TPC increased significantly from 20 to $27 \mathrm{mg} \mathrm{GAE} / \mathrm{g}$ following the increase in extraction temperature from 30 to $45^{\circ} \mathrm{C}$, after which TPC decreased (Fig. 1B). High temperature weakens the cell walls and increases the solubility and diffusion

Table 4. Comparison between predicted and experimental values for response variables of cumin at the given condition within the range of optimal condition

\begin{tabular}{cccc}
\hline Variables & Temperature $\left({ }^{\circ} \mathrm{C}\right)$ & Ethanol $(\%)$ & Extraction time $(\mathrm{min})$ \\
\hline Given condition & 39 & 40 & 51 \\
\hline Responses & Predicted value $(\mathrm{A})$ & Experimental value $(\mathrm{B})$ & $\mathrm{B} / \mathrm{A} \times 100(\%)$ \\
\hline Yield & 20.31 & $21.00 \pm 0.49^{2)}$ & 103.40 \\
TPC $^{1)}$ & 27.11 & $26.80 \pm 0.22$ & 98.86 \\
DPPH & 52.47 & $55.71 \pm 2.29$ & 106.17 \\
ABTS & 41.04 & $44.12 \pm 2.18$ & 107.50 \\
\hline
\end{tabular}

${ }^{1)} \mathrm{TPC}$, total polyphenolics content; DPPH, 2,2-diphenyl-1-picrylhydrazyl radical scavenging ability; ABTS, 2,2'-azinobis (3-ethylbenzothiazoline6-sulphonic acid) radical cation inhibition.

${ }^{2)}$ Mean \pm SD $(\mathrm{n}=3)$. 
coefficients of the extracted compounds, thereby facilitating mass passage through the solid substrate. (Yue et al., 2012). However, excessively high heat treatment can destroy the polyphenolic compounds due to the accelerated hydrolysis, internal redox reactions, and polymerization (Alonso-Salces et al., 2001).

The significance of temperature, ethanol concentration, and extraction time of UAE for different plant materials has been extensively studied (Al Juhaimi and Ghafoor, 2013; Knorr et al., 2004; Yue et al., 2012). Collectively, these results showed that a $60 \%$ ethanol concentration gives the highest TPC yield of $27.49 \mathrm{mg} \mathrm{GAE} / \mathrm{g}$, indicating a maximum appropriate polarity of ethanol concentration at 60\% (Al Juhaimi and Ghafoor, 2013; Yue et al., 2012).

An optimized extraction method with parameters of ethanol concentration $(53.6 \%)$, extraction temperature $\left(49^{\circ} \mathrm{C}\right)$, and extraction time $(2.8 \mathrm{~h})$ that could obtain the highest TPC yield (24.66 mg GAE/g) from cumin seeds using a shaking water bath has been reported (Al Juhaimi and Ghafoor, 2013). In our present study, similar conditions for temperature and ethanol concentration were observed, except the extraction time. Considering all results together, we demonstrated that UAE is a highly effective method that saves time and cost compared to the traditional extraction techniques. Knorr (2004) also reported that UAE increases the rate of mass transfer due to cavitation forces, by which the breaking of small vacuum bubbles in the liquid/solid can create localized pressure, accelerating the rupture of plant tissues and release of intracellular substances into the solvent.

\section{Effects of extraction condition on DPPH and ABTS radical scavenging activities}

The experimental data for DPPH assay are shown in Table 2. The correlation coefficients of the polynomial equation results were 0.9008 at a significance level of $\mathrm{p}<0.001$ (Table 3). The highest DPPH of $54.92 \%$ was detected in test run 4 under UAE conditions of ethanol concentration of $60 \%$, extraction temperature of $30^{\circ} \mathrm{C}$, and extraction time of $60 \mathrm{~min}$. Minimal DPPH (36.88\%) was obtained in test run 13 under UAE conditions of an extraction temperature of $45^{\circ} \mathrm{C}$, ethanol concentration of $0 \%$, and extraction time of $15 \mathrm{~min}$. The response surface plot for DPPH radical scavenging activity demonstrated the highest prediction point at values of the constant of $46,48,52$, and $56 \%$ (Fig. 1C). The extraction temperature of $15-45^{\circ} \mathrm{C}$, ethanol concentration of $40-60 \%$, and extraction time of 45-60 min showed good results for the DPPH radical scavenging activity of cumin seed extract. After optimization, the model predicted maximum DPPH radical scavenging activity of $52.47 \%$ under the following extraction conditions: extraction temperature of $39^{\circ} \mathrm{C}$, ethanol concentration of $40 \%$, and extraction time of $51 \mathrm{~min}$. The experimentally obtained amount of DPPH (55.71\%) was almost the same as the value predicted by the model $(52.47 \%$, Table 4$)$.

The experimental data for ABTS scavenging activity are presented in Table 2. The determination coefficient of the polynomial equation was 0.8882 at a significance level of $\mathrm{p}<0.001$ (Table 3). The highest ABTS of $44.59 \%$ was observed at $\mathrm{X}_{1}=60^{\circ} \mathrm{C}, \mathrm{X}_{2}=60 \%$, and $\mathrm{X}_{3}=30 \mathrm{~min}$ (Run 7, Table 2). The lowest ABTS of $26.08 \%$ was observed in run 9 under the following UAE conditions: extraction temperature of $15^{\circ} \mathrm{C}$, ethanol concentration of $40 \%$, and extraction time of $45 \mathrm{~min}$. The predicted maximum ABTS was $41.04 \%$ (Table 4). The response surface plot for ABTS radical scavenging activity indicated the highest predicted level at a constant quantity of 40,44, 48, and 52\% (Fig. 1D). Extraction temperature of $45-60^{\circ} \mathrm{C}$, ethanol concentration of $20-60 \%$, and extraction time of 45-60 min showed suitable results for ABTS radical scavenging activity of cumin seed extract. After optimization, the model predicted a maximum ABTS radical scavenging activity of $41.04 \%$ under the following extraction conditions: extraction temperature of $39^{\circ} \mathrm{C}$, ethanol concentration of $40 \%$, and extraction time of 51 min. The experimental ABTS value of $44.12 \%$ was similar to the model-predicted value $(41.04 \%$, Table 4$)$.

All the extraction conditions (extraction temperature, solvent concentration, and sonication time) had a considerable influence on the DPPH radical scavenging activity. However, the duration of extraction was observed to be of little importance to ABTS scavenging activity. Our results showed that the DPPH radical scavenging activity increased for a short time with increasing temperature, but at low temperature the activity was maintained over a longer period of extraction time. It has been suggested that the bioactive compounds in plant materials may not dissolve completely in the solution without heat treatment (Khatun et al., 2006), which can destroy the cell wall and the subcellular 
compartments of plant materials. Evidently, heat treatment or thermochemical reactions can be applied to increase the release and formation of radical-absorbing compounds (Maeda et al., 1992). Furthermore, Kishk and El-Sheshstawy (2010) proposed that increasing the temperature of ginger extraction led to a decrease in the radical scavenging activity due to the increased damage of phenolic compounds at higher temperature. Therefore, determining the optimal extraction temperature for the UAE is crucial.

The samples extracted with a $60 \%$ ethanol concentration had a better scavenging capacity for DPPH and ABTS radicals. The extraction time affects antioxidant activity due to the increased exposure duration of the solvent with solids, and thereby increases the diffusion of components (Ghafoor et al., 2009). The optimal extraction time for maximum absorption capacity of DPPH radicals was $60 \mathrm{~min}$. Cumin extracts obtained at $30 \mathrm{~min}$ showed greater scavenging capacity for ABTS radicals. This may be due to the fact that the antioxidant compounds in extracts obtained at various timepoints were examined in separate assays (DPPH and ABTS purification assays), as explained by Chang-Laing (2015).

\section{Optimization of process variables and model verification}

Suitable models for all responses were very significant and reliable in the experimental field, and canonical analysis confirmed that the critical points for all answers were maximum in the experimental field. The four-dimensional response surfaces were superimposed to predict the optimum UAE conditions, indicated by the maximum predicted peak at constant values for yield at $18-20 \%$, TPC at $24-28 \mathrm{mg}$ $\mathrm{GAE} / \mathrm{g}, \mathrm{DPPH}$ at $54-56 \%$, and ABTS at $46-52 \%$ (Fig. 2). Optimal UAE conditions were as follows: temperature $39^{\circ} \mathrm{C}$, ethanol concentration $40 \%$; and extraction time $51 \mathrm{~min}$, for predicted values of yield at $20.31 \%$, total polyphenol content at $27.11 \mathrm{mg} \mathrm{GAE} / \mathrm{g}$, DPPH at $52.47 \%$, and ABTS at $41.04 \%$ (Table 4). To confirm the accuracy and reliability of the predicted models, as well as to evaluate the deviation between the estimated and experimental values under the predicted optimal conditions, verification experiments was performed. Experimental values obtained were yield 21.0\%, total polyphenol content $26.8 \mathrm{mg} \mathrm{GAE} / \mathrm{g}$, DPPH $55.7 \%$, and ABTS $44.1 \%$ (Table 4). No significant differences were

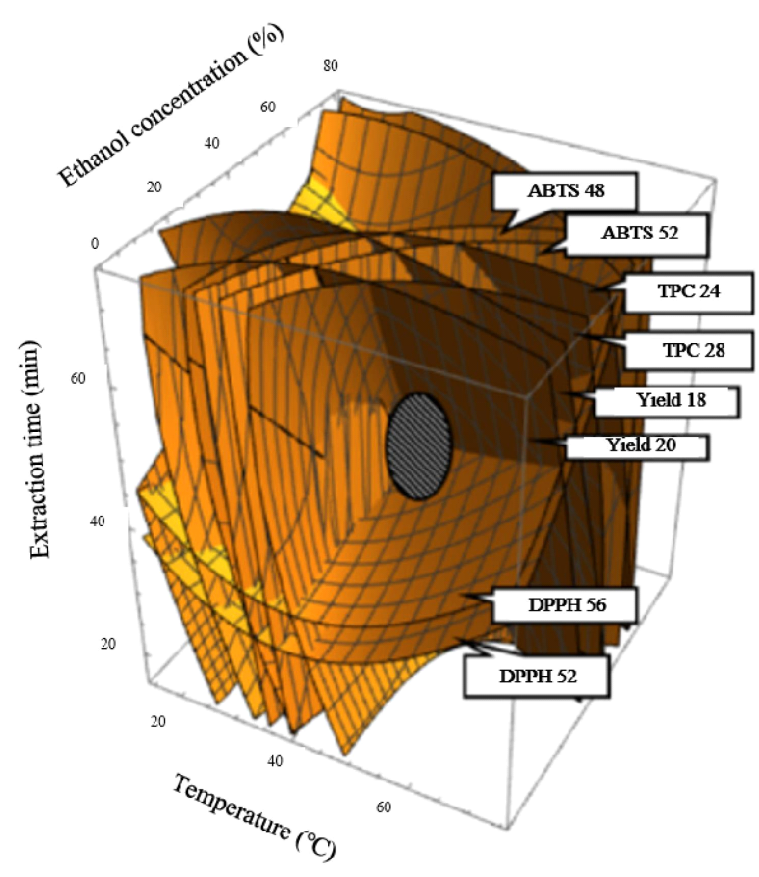

Fig. 2. Superimposed response surfaces at optimum UAE conditions. Superimposed response surface of total soluble solid, total polyphenol content, DPPH radical scavenging activity and DPPH radical scavenging activity for optimal UAE conditions cumin seeds extracts. Yield, $18-28 \%$; TPC, $24-28 \mathrm{mg}$ GAE/g; DPPH, 52-56\%; ABTS, $46-52 \%$ as a function of ethanol concentration (\%), extraction time (min), and extraction temperatures $\left({ }^{\circ} \mathrm{C}\right)$.

observed between the experimental and estimated values, thus verifying that the models fitted well with the experimental data and were valid and reliable. When compared to the predicted value substituted in the conformity model type, the experimental value appears to be $98.86-107.5 \%$ of the predicted value was recognized for the effectiveness of the extraction conditions (Table 4). Our results revealed that the predicted model is suitable for the high yield extraction of bioactive components from cumin under optimal UAE conditions, and the designed model is an ideal tool for predicting optimal extraction conditions.

\section{Phenolic compound composition of extract}

The phenolic compounds in cumin extract is shown in Table 5. The 9 phenolic compounds (catechin, caffeic acid, syringic acid, $p$-coumaric acid, rutin, ferulic acid, myricetin, quercetin, and kaempferol) were identified from extract. Among them, myricetin and rutin were predominant compounds. The composition of phenolic compound was different with previous studies (Rebey et al., 2012a; Rebey 
Table 5. Phenolic compounds in cumin extract

\begin{tabular}{|c|c|c|c|c|c|c|c|c|c|}
\hline & $\begin{array}{l}\text { Caffeic } \\
\text { acid }\end{array}$ & $\begin{array}{l}\text { Syringic } \\
\text { acid }\end{array}$ & $\begin{array}{l}p \text {-Coumaric } \\
\text { acid }\end{array}$ & $\begin{array}{l}\text { Ferulic } \\
\text { acid }\end{array}$ & Rutin & Catechin & Myricetin & Quercetin & Kaempferol \\
\hline $\begin{array}{l}\text { Phenolic } \\
\text { compounds } \\
\text { (mg/g) }\end{array}$ & $0.72 \pm 0.00$ & $0.11 \pm 0.00$ & $5.04 \pm 0.01$ & $9.81 \pm 0.07$ & $16.22 \pm 1.34$ & $6.51 \pm 0.08$ & $34.59 \pm 0.57$ & $1.85 \pm 0.02$ & $0.69 \pm 0.00$ \\
\hline
\end{tabular}

et al., 2012b). This difference may be attributed by various factors, such as environmental factor and extraction condition (Rebey et al., 2012a; Rebey et al., 2012b).

\section{Conclusion}

This study was focused on to find optimal extraction conditions to extract of bioactive compounds from cumin seeds operating the ultrasonic-assisted extraction method. This method of extraction is an ecologically sustainable technique with very effective, lower power-efficient, and without applying of high pressure or temperature. Thus, phytochemical compounds can be extracted from natural plants at considerably low temperatures without undergoing thermal decomposition, maintaining their original form for biological activity analysis. In the present study, bioactive compounds such as polyphenols and antioxidants were rapidly extracted from cumin seeds using UAE. Based on the results the optimal UAE conditions were an temperature of $39^{\circ} \mathrm{C}$, concentration of ethanol $40 \%(\mathrm{v} / \mathrm{v})$ and $51 \mathrm{~min}$ of extraction time supposed using superimposed surface plots, that provides the expected highest amounts of yield (20.31\%), TPC (27.11 mg GAE/g), antioxidant activity DPPH (52.47\%) and ABTS (41.04\%). Optimal conditions for maximal UAE extraction of TPC, DPPH, ABTS radical-scavenging activity and extract yield of Cumin (Cuminum cyminum) seeds have been effectively established by RSM. The HPLC analysis was performed to identify phenolic compounds in the extract, which obtained from optimal extraction condition. The results showed that extract include the catechin, caffeic acid, syringic acid, $p$-coumaric acid, rutin, ferulic acid, myricetin, quercetin, and kaempferol.

\section{Acknowledgement}

The authors would like to thank the Korean International Cooperation Agency (KOICA) for providing scholarship to the first author (Anvar Shamsiev).

\section{Conflict of interests}

The authors declare no potential conflict of interest.

\section{ORCID}

Anvar Shamsiev https://orcid.org/0000-0002-2379-4283

Wonyoung Lee https://orcid.org/0000-0001-5850-9692

\section{References}

Agrawal D, Sharma L, Rathore S, Zachariah T, Saxena S. Analysis of total phenolics and antioxidant activity in seed and leaf extracts of cumin genotypes. Int $\mathrm{J}$ Seed Spices, 6, 43-49 (2016)

Al Juhaimi F, Ghafoor K. Extraction optimization and in vitro antioxidant properties of phenolic compounds from cumin (Cuminum cyminum L.) seed. Int Food Res J, 20, 1669-1675 (2013)

Alonso-Salces RM, Korta E, Barranco A, Berrueta L, Gallo B, Vicente F. Pressurized liquid extraction for the determination of polyphenols in apple. J Chromatogr A, 933, 37-43 (2001)

Bimakr M, Rahman RA, Taip FS, Adzahan NM, Sarker M, Islam Z, Ganjloo A. Optimization of ultrasound-assisted extraction of crude oil from winter melon (Benincasa hispida) seed using response surface methodology and evaluation of its antioxidant activity, total phenolic content and fatty acid composition. Molecules, 17, 11748-11762 (2012)

Blois MS. Antioxidant determinations by the use of a stable free radical. Nature, 181, 1199-1200 (1958)

Bukhari SB, Iqbal S, Bhanger M. Antioxidant potential of commercially available cumin (Cuminum cyminuml inn) in Pakistan. Int J Food Sci Nutr, 60, 240-247 (2009)

Corrales M, Toepfl S, Butz P, Knorr D, Tauscher B. Extraction of anthocyanins from grape by-products assisted by ultrasonics, high hydrostatic pressure or 
pulsed electric fields: A comparison. Innov Food Sci Emerg Technol, 9, 85-91 (2008)

Domingos AK, Saad EB, Wilhelm HM, Ramos LP. Optimization of the ethanolysis of Raphanus sativus (L. var.) crude oil applying the response surface methodology. Bioresour Technol, 99, 1837-1845 (2008)

Ghafoor K, Choi YH, Jeon JY, Jo IH. Optimization of ultrasound-assisted extraction of phenolic compounds, antioxidants, and anthocyanins from grape (Vitis vinifera) seeds. J Agric Food Chem, 57, 4988-4994 (2009)

Haji A, Qavamnia SS. Response surface methodology optimized dyeing of wool with cumin seeds extract improved with plasma treatment. Fibers Polym, 16, 46-53 (2015)

Ilghami A, Ghanbarzadeh S, Hamishehkar H. Optimization of the ultrasonic-assisted extraction of phenolic compounds, ferric reducing activity and antioxidant activity of the Beta vulgaris using response surface methodology. Pharm Sci, 21, 46-50 (2015)

Jing CL, Dong X-F, Tong J-M. Optimization of ultrasonicassisted extraction of flavonoid compounds and antioxidants from alfalfa using response surface method. Molecules, 20, 15550-15571 (2015)

Khatun M, Eguchi S, Yamaguchi T, Takamura H, Matoba T. Effect of thermal treatment on radical-scavenging activity of some spices. Food Sci Technol Res, 12, 178-185 (2006)

Kishk Y, El Sheshetawy H. Optimization of ginger (Zingiber officinale) phenolics extraction conditions and its antioxidant and radical scavenging activities using response surface methodology. World J Dairy and Food Sci, 5, 188-196 (2010)

Knorr D, Zenker M, Heinz V, Lee DU. Applications and potential of ultrasonics in food processing. Trends Food Sci Technol, 15, 261-266 (2004)

Maeda H, Katsuki T, Akaike T, Yasutake R. High correlation between lipid peroxide radical and tumor promoter effect: Suppression of tumor promotion in the Epstein-Barr virus/B-lymphocyte system and scavenging of alkyl peroxide radicals by various vegetable extracts. Jpn J Cancer Res, 83, 923-928 (1992)

Myers RH, Montgomery DC, Anderson-Cook CM. Response Surface Methodology: Process and Product
Optimization Using Designed Experiments. John Wiley \& Sons, New York, USA, p219-280 (2009)

Nadeem M, Riaz A. Cumin (Cuminum cyminum) as a potential source of antioxidants. Pak J Food Sci, 22, 101-107 (2012)

Ong ES. Extraction methods and chemical standardization of botanicals and herbal preparations. J Chromatogr B, 812, 23-33 (2004)

Rebey IB, Bourgou S, Debez IBS, Karoui IJ, Sellami IH, Msaada K, Limam F, Marzouk B. Effects of extraction solvents and provenances on phenolic contents and antioxidant activities of cumin (Cuminum cyminum L.) seeds. Food and Bioprocess Technol, 5, 2827-2836 (2012a)

Rebey IB, Jabri-Karoui I, Hamrouni-Sellami I, Bourgou S, Limam F, Marzouk B. Effect of drought on the biochemical composition and antioxidant activities of cumin (Cuminum cyminum L.) seeds. Ind Crop Prod, 36, $238-245$ (2012b)

Seal T. Quantitative HPLC analysis of phenolic acids, flavonoids and ascorbic acid in four different solvent extracts of two wild edible leaves, Sonchus arvensis and Oenanthe linearis of North-Eastern region in India. J Appl Pharm Sci, 6, 157-166 (2016)

Shalaby EA, Shanab SM. Comparison of DPPH and ABTS assays for determining antioxidant potential of water and methanol extracts of Spirulina platensis. Indian J Mar Sci, 42, 556-564 (2013)

Singleton VL, Orthofer R, Lamuela-Raventos RM. Analysis of total phenols and other oxidation substrates and antioxidants by means of Folin-Ciocalteu reagent. Methods Enzymol, 299, 152-178 (1999)

Sowbhagya H. Chemistry, technology, and nutraceutical functions of cumin (Cuminum cyminum L.): An overview. Crit Rev Food Sci Nutr, 53, 1-10 (2013)

Srinivasan K. Cumin (Cuminum cyminum) and black cumin (Nigella sativa) seeds: Traditional uses, chemical constituents, and nutraceutical effects. Food Qual Saf, 2, $1-16$ (2018)

Sultana S, Ripa F, Hamid K. Comparative antioxidant activity study of some commonly used spices in Bangladesh. Pak J Biol Sci, 13, 340 (2010)

Teng H, Lee WY, Choi YH. Optimization of ultrasonicassisted extraction of polyphenols, anthocyanins, and 
antioxidants from raspberry (Rubus coreanus Miq.) using response surface methodology. Food Anal. Methods, 7, 1536-1545 (2014)

Tomsik A, Pavlic B, Vladic J, Ramic M, Brindza J, Vidovic S. Optimization of ultrasound-assisted extraction of bioactive compounds from wild garlic (Allium ursinum L.). Ultrason Sonochem, 29, 502-511 (2016)

Tuncturk R, Tuncturk M. Effects of different phosphorus levels on the yield and quality components of cumin (Cuminum cyminum L.). Res J Agric Biol Sci, 2, 336340 (2006)
Vinatoru M, Toma M, Radu O, Filip P, Lazurca D, Mason $\mathrm{T}$. The use of ultrasound for the extraction of bioactive principles from plant materials. Ultrason Sonochem, 4, 135-139 (1997)

Wang J, Sun B, Cao Y, Tian Y, Li X. Optimisation of ultrasound-assisted extraction of phenolic compounds from wheat bran. Food Chem, 106, 804-810 (2008)

Yue T, Shao D, Yuan Y, Wang Z, Qiang C. Ultrasoundassisted extraction, HPLC analysis, and antioxidant activity of polyphenols from unripe apple. J Sep Sci, 35, 2138-2145 (2012) 